\title{
VARIOUS INEQUALITIES RELATED TO THE ADAMS INEQUALITY ON WEIGHTED MORREY SPACES
}

\author{
TAKESHI IIDA
}

Abstract. We consider various inequalities related to the Adams inequality for the fractional integral operators on weighted Morrey spaces. In 2014, Izumi, Komori-Furuya and Sato proved an inequality which is the type of the Adams inequality on weighted Morrey spaces. Firstly, we investigate another proof of their result. Secondly, we investigate various inequalities related to their result for higher order commutators generated by BMO-functions and the fractional integral operator on weighted Morrey spaces. One of the main results in this papar recovers the result due to Cruz-Uribe and Fiorenza in 2003. Thirdly, we extend the fractional integrals to the multilinear fractional integrals. The result of the multilinear fractional integrals partially recovers the Moen result.

Mathematics subject classification (2010): 26A33, 42B25.

Keywords and phrases: Weights, weighted Morrey spaces, fractional integral operator, multilinear fractional integral operator, homogeneous kernels, BMO spaces, commutator.

\section{REFERENCES}

[1] D. Adams, A note on Riesz potentials, Duke Math. J. 42 (1975), 765-778.

[2] S. Chanillo, A note on commutator, Indiana Univ. Math. J. 31 (1982), 7-16.

[3] S. Chen, H. Wu AND Q. Xue, A note on multilinear Muckenhoupt classes for multiple weights, Studia Math. 223 (2014), 1-18.

[4] X. Chen AND Q. XUE, Weighted estimates for a class of multilinear fractional type operators, J. Math. Anal. Appl. 362 (2010), 355-373.

[5] D. CruZ-Uribe AND A. FiorenZA, Endpoint estimates and weighted norm inequalities for commutators of fractional integrals, Publ. Mat. 47 (2003), 103-131.

[6] G. Di Fazio And M. A. Ragusa, Commutators and Morrey spaces, Bollettino U. M.I. 7 (1991), 323-332.

[7] Y. DING AND S. LU, Weighted norm inequalities for fractional integral operators with rough kernel, Can. J. Math. 50 (1998), 29-39.

[8] J. Duonndikoetxea, Fourier Analysis, Grad. Studies in Math. 29. Amer. Math. Soc., Providence, RI, 2001.

[9] J. GARCía-Cuerva AND J. L. Rubio de Francia, Weighted norm inequalities and related topics, North-Holland Math. Stud., 116, 1985.

[10] L. GRafakos, Modern Fourier analysis, Second Edition, Graduate Texts in Math., 250, Springer, New York, 2008.

[11] L. I. Hedberg, On certain convolution inequalities, Proc. Amer. Math. Soc. 36 (1972), 505-510.

[12] T. IIDA, A characterization of a multiple weights class, Tokyo J. Math. 35 (2012), 375-383.

[13] T. IIDA, Weighted inequalities on Morrey spaces for linear and multilinear fractional integrals with homogeneous kernels, Taiwanese J. Math., 181 (2014), 147-185.

[14] T. IIDA, Weighted estimates of higher order commutators generated by BMO-functions and the fractional integral operator on Morrey spaces, Journal of Inequalities and Applications 2016, 23 pp.

[15] T. IIDA, E. SATO, Y. SAWANO AND H. TANAKA, Sharp bounds for multilinear fractional integral operators on Morrey type spaces, Positivity 16 (2012), 339-358. 
[16] T. IIDA, E. SATO, Y. SAWANO AND H. TANAKA, Weighted norm inequalities for multilinear fractional operators on Morrey spaces, Studia Math. 205 (2011), 139-170.

[17] T. IZUMI, Y. KOMORI-FURUYA AND E. S ATO, The fractional integral operators related to the Adams inequality on weighted Morrey spaces, Sci. Math. J. 77 (2014), 169-175.

[18] Y. Komori And T. Mizuhara, Notes on commutators and Morrey spaces, Hokkaido. Math. J. 32 (2003), 345-353.

[19] Y. KOMORI AND S. SHIRAI, Weighted Morrey spaces and a singular integral operator, Math. Nachr. 282 (2009), 219-231.

[20] S. Lu, Y. Ding AND D. YAn, Singular integrals and related topics, World Scientific publishing, Singapore, 2007.

[21] A. K. LERNER, An elementary approach to several results on the Hardy-Littlewood maximal operator, Proc. Amer. Math. 136 (2008), 2829-2833.

[22] K. MoEN, Weighted inequalities for multilinear fractional integral operators, Collect. Math. 60 (2009), 213-238.

[23] B. Muckenhoupt And R. Wheeden, Weighted norm inequalities for fractional integrals, Trans. Amer. Math. Soc. 192 (1974), 261-274.

[24] P. Olsen, Fractional integration, Morrey spaces and Schrödinger equation, Comm. Partial Differential Equations 20 (1995), 2005-2055.

[25] J. PeETRE, On the theory of $\mathscr{L}_{p, \lambda}$ spaces, J. Funct. Anal. 4 (1969), 71-87.

[26] C. PÉrez, Sharp $L^{p}$-weighted Sobolev inequalities, Ann. Inst. Fourier (Grenoble) 45 (1995), 809824.

[27] Y. Sawano And H. TANAKa, Morrey spaces for non-doubling measures, Acta Math. Sinica 6 (2005), 1535-1544.

[28] Y. Sawano, S. Sugano And H. TANAKa, Generalized fractional integral operators and fractional maximal operators in the framework of Morrey spaces, Trans. Amer. Math. Soc. 12 (2011), 64816503.

[29] Y. Sawano, S. Sugano And H. TANAKa, Olsen's inequality and its applications to Schrödinger equations, Suuricakiseki Kôkyûroku Bessatsu, B26, Harmonic Analysis and Nonlinear Partial Differential Equations (2011), 51-80.

[30] Y. SAWANO, S. SUGANO AND H. TANAKA, A bilinear estimate for commutators of fractional integral operators, Suuricakiseki Kôkyûroku Bessatsu, B43, Potential Theory and Its Related Fields (2013), $155-170$.

[31] E. M. Stein, Singular integrals and differentiablity properties of functions, Princeton University Press, NJ, 1970. 